\title{
First Record of Identification of RPMS1 Gene Variations in Vietnamese Nasopharyngeal Carcinoma Patients
}

\author{
Duc Thuan Lao', Danh Hoang Nguyen', Minh Trong Quang', \\ Hue Hong Thieu ${ }^{2}$ and Thuy Ai Huyen Le ${ }^{1}$ \\ 'Faculty of Biotechnology, Ho Chi Minh City Open University, 97 Vo Van Tan Str., Ward 6, District 3 \\ Ho Chi Minh City - 700000, Vietnam; ducthuanlao87@gmail.com, thuan.Id@ou.edu.vn, \\ danhhoang1804@gmail.com, tmquang99@gmail.com, thuy.lha@ou.edu.vn \\ ${ }^{2}$ Faculty of Biology and Biotechnology, University of Science, Vietnam National University, Ho Chi Minh City, \\ 227 Nguyen Van Cu Str., Ward 4, District 5 - 700000, Vietnam; honghue0205@gmail.com
}

\begin{abstract}
Epstein-Barr Virus (EBV) infection and EBV genes' variation are considered as the etiological factors contributed to NasoPharyngeal Carcinoma (NPC). In the latent EBV stage, not only the latent membrane proteins but also RPMS1 expression has been confirmed in all EBV-associated tumors. In Vietnam, an Asian country with the high incidence, mortality rate of NPC, had limit research on the RMPS1 gene variation. Therefore, the objects of current study were to identify the pattern of RMPS1 variations in Vietnamese NPC patients for its value further applied in NPC patients. In this study, thirty NPC biopsy samples and thirty non-cancerous swab specimens were collected from local patients, analyzed by PCR, sequencing and compared to previous B95-8 sequence. As the results, the strongly association between the detection of RPSM1 gene and NPC incidence in Vietnamese NPC patients was determined. Additionally, the RMPS1 gene variants, including wild-type, RMPS1-B, RMPS1-C, RMPS1-C*, were identified. Among them, RMPS1-C/C* was preferential in Vietnamese nasopharyngeal cancer. In conclusion, those data is the first dataset on the polymorphism in the RPMS1 gene in Vietnamese NPC patients, and could be utilized as a promising biomarker for prognosis, diagnosis and therapy for NPC based on the EBV gene variations.
\end{abstract}

Keywords: Nasopharyngeal Carcinoma, RPMS1, Variations

\section{Introduction}

The epidemiology of Naso-Pharyngeal Carcinoma (NPC), a prevalent malignant tumor of nasopharynx, has remarkably characterized by its distinctive geographic and ethnic contribution, gravitating toward Southern Asia. Vietnam has one of the highest incidence rates of NPC in worldwide ${ }^{1,2}$. According to statistics of Globocan (2012), the high prevalence of NPC cases was observed in reached to 4,931 cases $(\mathrm{ASR}=5.4 / 100,000)$ and deaths was 2,885 cases (ASR $=3.3 / 100,000)$ in Vietnamese population $^{3}$. For the past few years, many studies have been demonstrated that the major etiological factors proposed for NPC pathogenesis, including Epstein-Barr virus (EBV) infection, genetics/or epigenetic changes and environmental factor ${ }^{4-8}$. In the latent EBV stage, additionally to the latent membrane proteins (LMP1, LMP-2), and small noncoding RNAs (EBERs), as

*Author for correspondence 
the member of the BamHI-A Rightward Transcripts (BARTs) family, RPMS1 expression has been confirmed in all EBV-associated tumors ${ }^{9-13}$. A number of studies have reported attempts to identify the NPC associated EBV genes' variations, including EBV Nuclear Antigens (EBNAs), Latent Membrane Proteins (LMPs) and EBVencoded small nuclear RNAs (EBERs), have been shown to be associated with NPC pathogenesis ${ }^{14-17}$. However, few studies have investigated the single nucleotide polymorphisms (SNPs) of RPMS1 gene, as the reported, only one SNP site (locus: $155391 \mathrm{G}>\mathrm{A}$, named G155391A) is identified and significantly associated with NPC incidence ${ }^{16,18}$. They found that the RPMS1 variation (G155391A) functionally relevant to regulating the PRMS1 protein stability and over expressed in vitro ${ }^{16}$.

Vietnam, located in Southern Asia, is well known as the high incidence and mortality rate of nasopharyngeal carcinoma in the world. According to EBV infection, the rate of EBV positive in NPC patients is high ${ }^{17}$. However, limited studies were carried on the genotyping of EBV as well as the variations of EBV genes. In previous studies, we established the protocol for genotyping of EBNA-1 subtype from of nasopharyngeal biopsy samples collected from Vietnamese nasopharyngeal carcinoma patients, and the results suggested the $\mathrm{V}$-val subtype is the preferentially subtype associated with nasopharyngeal carcinoma. To further identify the EBV variations linked to NPC risks, we conducted the analysis on the RPMS1 gene, a member of BARTs family, in the comparison to the prototype B95-B strain, starting from NPC biopsy samples and healthy controls in the Vietnamese population. Therefore, our objective was to develop the simple method to identify the RPMS1 gene's polymorphisms at Vietnamese population.

\section{Materials and Methods}

\subsection{Ethics Statement}

Institutional Ethics Board approval, the decision number of the permission from Ethical committee: 516/BVCR-
HDDD, was obtained from the Medical Ethics Committee of the Cho Ray Hospital, Ho Chi Minh City, Vietnam. All the biopsy samples used in current study were collected from participants, who agreed and signed on the consent forms.

\subsection{Samples Collection, and DNA Isolation}

Thirty nasopharyngeal carcinoma biopsy samples were collected from local patients, in Cho Ray Hospital, Ho Chi Minh City, Vietnam. The entire sample was submitted to the histopathological diagnosis center to confirm the NPC. Notably, all of those biopsies were collected from patients, who were obeyed to ethical approval for study human samples, and patients agreed with purpose of the study. In addition, thirty nasopharyngeal swab samples, which were collected from healthy donors, used as negative-nasopharyngeal carcinoma control.

For DNA isolation, biopsies were lysed in lysis buffer, containing $10 \mathrm{mM}$ Tris- $\mathrm{HCl} \mathrm{pH}=8,10 \mathrm{mM}$ EDTA, $150 \mathrm{mM} \mathrm{NaCl}, 2 \%$ SDS, and $0.1 \mathrm{mg} / \mathrm{ml}$ Proteinase $\mathrm{K}$, incubated in $56^{\circ} \mathrm{C}$, overnight. Total of genomic DNA of clinical samples were extracted by using Phenol/ Chloroform solution, $\mathrm{pH}=8$. The purification of DNA was done by Ethanol solution $99 \%$. The quality and purity of DNA isolates were measured by the evaluation of $\mathrm{A}_{260} /$ $\mathrm{A}_{280}$ proportion. The DNA solution was stored in TrisEDTA $0.5 \mathrm{M}$, at $-20^{\circ} \mathrm{C}$ for further assays.

\subsection{PCR-sequencing of RPMS1 Gene}

Multiplex PCR assay was applied for the amplification of RPMS1 gene and beta-actin gene, which served as the internal control. The sequence and position of primers were shown in (Table 1).

The PCR assay was performed in a total of $15 \mu \mathrm{L}$, containing $100 \mathrm{ng}$ genomic DNA templates, $0.25 \mu \mathrm{M}$ each primer, and 7.5 $\mu \mathrm{L}$ MyTaqTM Mix (Bioline, Cat No. BIO-25041). PCR amplification was performed with an initial denaturation at $94^{\circ} \mathrm{C}$ for 5 minutes; followed by 45 cycles of denaturation at $94^{\circ} \mathrm{C}$ for 30 seconds, annealing at $60^{\circ} \mathrm{C}$ for 30 seconds, extension at $72^{\circ} \mathrm{C}$ for 30 seconds; and

Table 1. Primers' sequences used in current study

\begin{tabular}{|l|l|l|l|}
\hline Target genes & Primer & Sequence $\left(\mathbf{5}^{\prime} \mathbf{-} \mathbf{3}^{\prime}\right)$ & Reference \\
\hline \multirow{2}{*}{ RPMS1 } & RPMS1-F & GCTGGGTTGATGCTGTAGATG & 16 \\
\cline { 2 - 4 } & RPMS1-R & AGGGTCTGGACGTGGAGTTTG & \\
\hline \multirow{2}{*}{ Beta-actin } & Beta-F & ATCATGTTTGAGACCTTCAACAC & \\
\cline { 2 - 4 } & Beta-R & CATCTCTTGCTCGAAGTCCAG & \\
\hline
\end{tabular}


elongation step at $72^{\circ} \mathrm{C}$ for 10 minutes. The PCR products were visualized and analyzed by electrophoresis through stained with Ethidium bromide, and $2.0 \%$ agarose gel. For RPMS1 gene sequencing, $30 \mu \mathrm{L}$ products were sent to Nam Khoa Biotek Co. Ltd. (Vietnam) for directly sequencing in both directions with primer of RPMS1.

\subsection{Determination and Analysis of RPMS1 Variations}

The results of RPMS1 sequencing was read by Chromas 2.6.4 (Technelysium) and checked for sequencing homology by using BLAST (NCBI). For determination of RPMS1 variations, the sequencing of RPMS1 of current study were compared to the B95-8 strain (Genbank accession number: NC_007605; Gene RPMS1's Location 138352..160531). The alignment between data sequence and B95-8 strain sequence were analyzed by using BioEdit sequence alignment editor.

\section{Results}

\subsection{Association between RMPS1 and NPC Incidence}

The frequency of RPMS1 gene in NPC biopsy samples and healthy samples were detected by PCR method. The PCR product sizes, 319-bps and 733-bps bands, were different which is easy to be distinguished on electrophoresis results, shown in (Figure 1). The human beta-actin PCR product of 319 bps gave the indication on the good quality of the extracted DNA and PCR assay. Overall, the frequency of RPMS1 in NPC samples was $66.67 \%$ (20 of 30 samples). In non-NPC swab samples, no RPMS1-positive case was detected. Based on the statistical analysis, the presence of RPMS1 was found to be significantly associated with NPC ( $\mathrm{p}<0.05)$. Additionally, the 733-bp product, which indicated the presence of RMPS1, was determined by Sanger sequencing. The signals of peaks in PCR product sequencing were good for nucleotide reading (Figure 2). According to BLAST results, candidate gene's sequence was similar to Human gammaherpes virus 4 (Accession number: $\mathrm{MH} 144220$ ) within the Total score $=1216$, ident $=99.85 \%$, E-value $=0.0$.

\subsection{Identification of RPMS1 Gene Variations: RPMS1-C Variation was Preferential in Vietnamese Nasopharyngeal Cancer}

RPMS1 gene was successfully amplified, observed in a distinct band with 733 bps, shown in Figure 1 and sequenced in 20 of 30 NPC samples. The nucleotide variations were determined by mapping and comparing to the RPMS1 gene of wild-type EBV genome (GenBank Accession No. NC_007605: location 138352..160531). As the results, nice NPC samples (counting for 45.0\%) were similar to the wild-type EBV's RPMS1 gene. The polymorphisms point G155391A, classified as RPMS1-C, was discovered in 10 NPC samples (counting for 50.0\%). Of these, 1 NPC sample differentially distributed substitution G155391A and one silent polymorphism

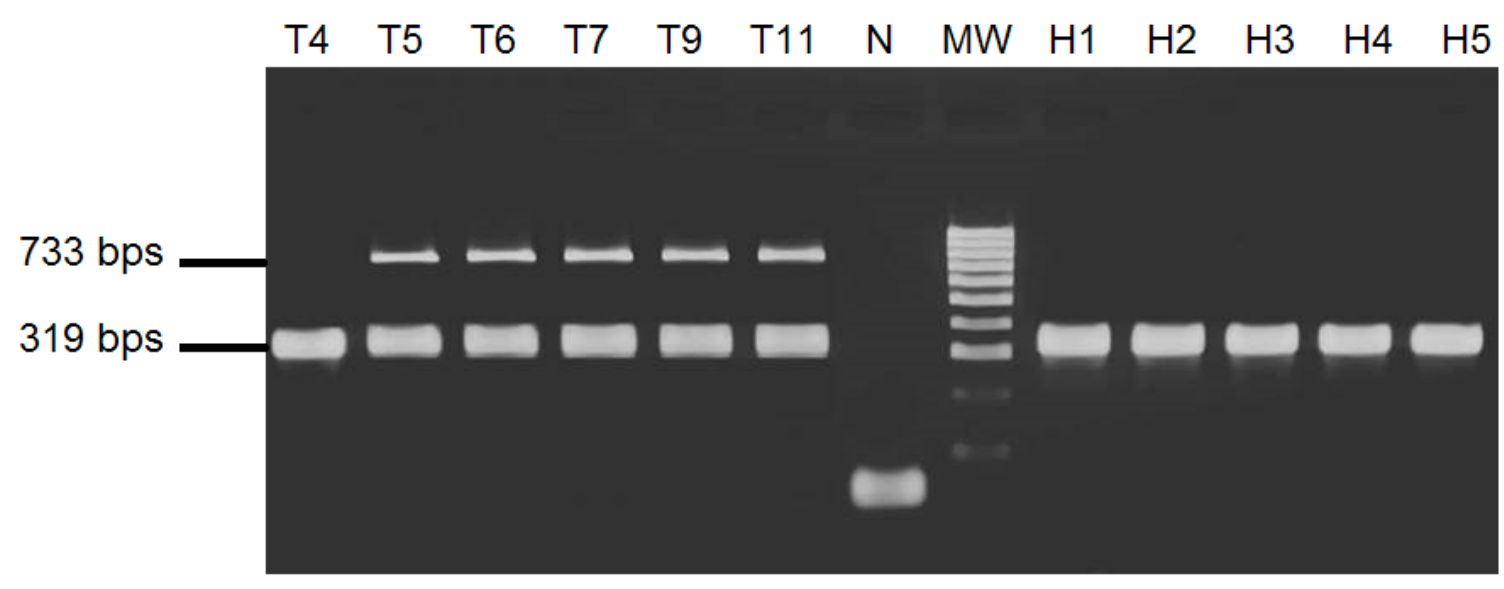

Figure 1. Electrophoresis of Nested-PCR products of representative clinical samples: T4, T5, T6, T7, T11: clinical biopsy samples; H1, H2, H3, H4, H5: Healthy (non-NPC) swab samples; N: negative control; MW: molecular weight 100 bps. 


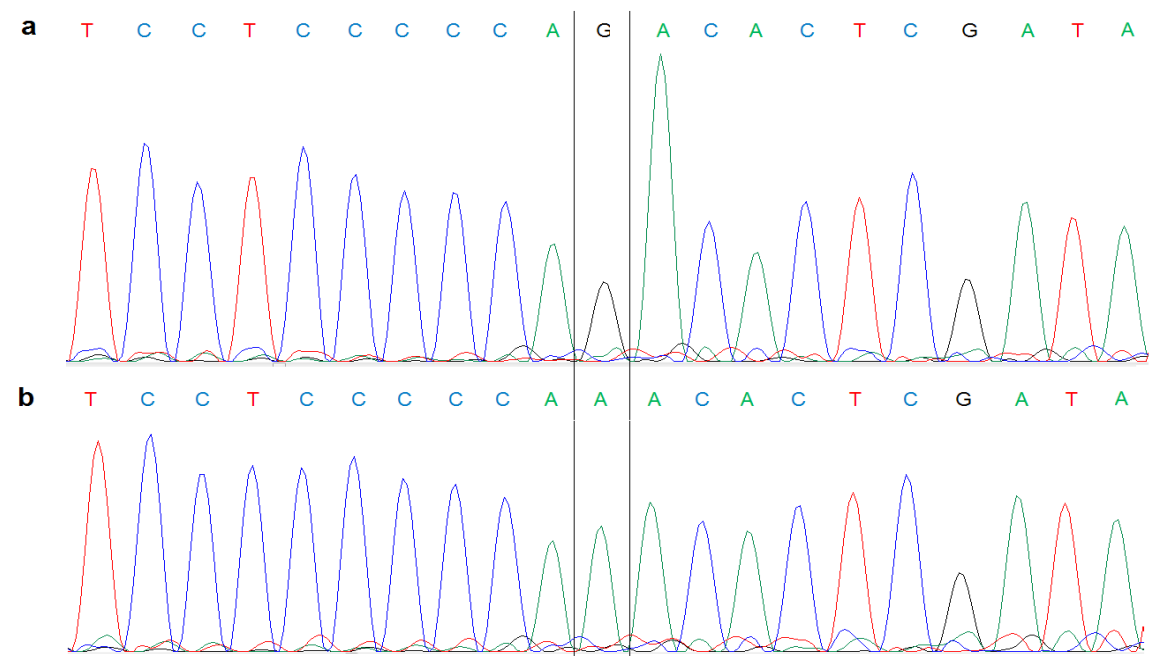

(A)

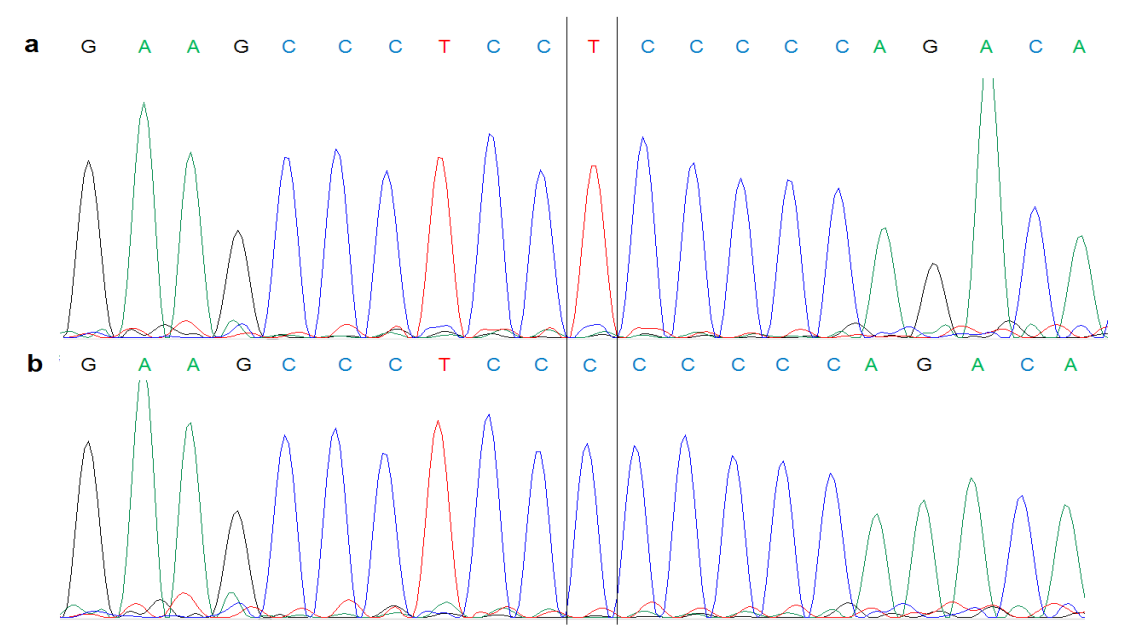

(B)

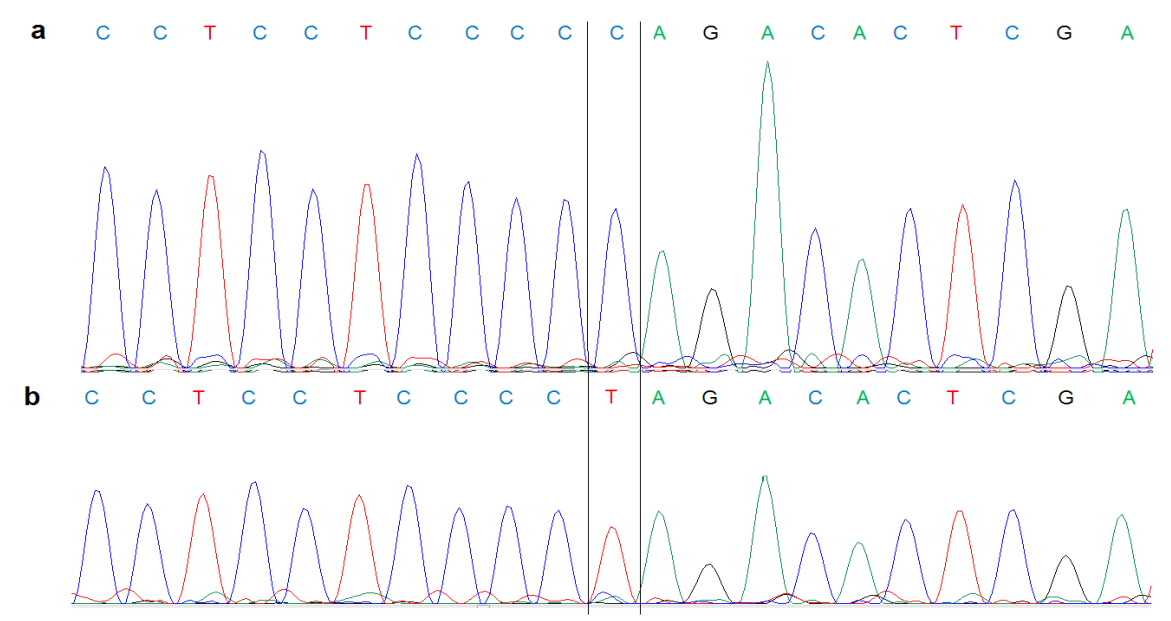

(C)

Figure 2. Validation of the RPMS1 single nucleotide polymorphism (A) G155391A; (B) T155384C; (C) C155389T in representative NPC samples by Sanger sequencing. (a) wild type RPMS1 gene (NC_007605); (b) representative SNPs identified samples. 
site as T155384C, classified as RPMS1-C* (Figure 2A, B). Moreover, only one sample, counting for $5.00 \%$, within the substitution C155389T, classified as RPMS1-B, was determined (Figure 2C) (Table 2). Therefore, RPMS1-C variation was preferential in Vietnamese nasopharyngeal cancer.

All the nucleotide variations of sequencing, encoded the amino acid residue 48, 50, 51 of RPMS1 gene, of 20 cases were determined by comparing with the B958. As the results, three patterns of RPMS1, including RPMS1-B, RPMS1-C, RPMS1-C*, and wild type (Wt), were determined (Table 2). In detail, Wt (amino acid at 51 (GAC:Asp), representatively reported by T6), RPMS1-B (the amino acid change was at residue 50 (CCA:Pro>CTA:Leu), representatively T22), RPMS1-C and RPMS1-C* (the amino acid change was at residue 51 (GAC:Asp>AAC:Asn), representatively reported by T5), were similar to previous studies. The RPMS1-C and RPMS1-C* shared the same pattern, in spite of the T155384C occurred in RPMS1.

\section{Discussion}

In current study, we successfully amplified RPMS1 gene from NPC biopsy samples by multiplex-PCR with the internal control - beta actin. Notably, to our knowledge, the current study is the initial study, which recorded the determination of RPMS1 polymorphisms in total of 20 RPMS1-positive samples collected from Vietnamese NPC patients. As the results, T155384C variant was identified as the novel variant of RPMS1 variations from Vietnamese nasopharyngeal carcinoma patients. However, this variant did not effected the primary structure of translated protein, due to the silence substitution (CCT: Pro $>$ CCC:Pro). Therefore, in summary, three patterns, RPMS1-B, RPMS1-C/C*, and $\mathrm{Wt}$, were identified. In previous studies, four RPMS1 patterns were determined and clustered as RPMS1-A, RPMS1-B, RPMS1-C and RPMS1-D (compared to wild type EBV genome). A RPMS1-C pattern variation was represented by the RPMS1 SNP G155391A (amino acid residue GAC:Asp>AAC:Asn). This variation has been reported to be associated with a high risk of $\mathrm{NPC}^{16}$. According to Feng et al., they suspected that the variation of G155391A from Guanine to Adenine, leading to the amino acid change from Aspartic acid (Asp) to Asparagine (Asn), might related to the expression of $R P M S 1^{16}$. In detail, the variations of G155391A are functionally relevant to the stability of RPMS1, which is in a longer half life of RPMS1 protein and may exhibit stronger carcinogenesis potential. Additionally, the oncogenic RPMS1 has shown to promote the cell differentiation and proliferation, thus,

Table 2. Nucleotide and amino acid substitution in RPMS1 gene compared to wild type B95-8 sequence

\begin{tabular}{|c|c|c|c|c|c|c|c|c|c|c|c|}
\hline \multirow[t]{4}{*}{ Patterns } & Nucleotide Position & 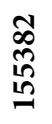 & $\begin{array}{l}n \\
\infty \\
n \\
10 \\
n\end{array}$ & 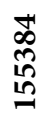 & $\begin{array}{l}\infty \\
\infty \\
n \\
10 \\
10\end{array}$ & $\begin{array}{l}2 \\
\infty \\
10 \\
10 \\
1\end{array}$ & 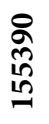 & $\begin{array}{l}\text { बे } \\
\hat{n} \\
\text { مी }\end{array}$ & $\begin{array}{l}\text { న్ } \\
\text { กิ } \\
\text { م̂ }\end{array}$ & $\begin{array}{l}\text { â } \\
\text { in } \\
\text { ñ }\end{array}$ & Frequency \\
\hline & \multirow[t]{2}{*}{ Wild type (NC_007605) } & $\mathrm{C}$ & $\mathrm{C}$ & $\mathbf{T}$ & $\mathrm{C}$ & $\mathrm{C}$ & A & G & A & $\mathrm{C}$ & \\
\hline & & \multicolumn{3}{|c|}{ Pro } & \multicolumn{3}{|c|}{ Pro } & \multicolumn{3}{|c|}{ Asp } & \\
\hline & Codon & \multicolumn{3}{|c|}{48} & \multicolumn{3}{|c|}{50} & \multicolumn{3}{|c|}{51} & \\
\hline \multirow[t]{2}{*}{ RPMS1-B } & \multirow[t]{2}{*}{$\mathrm{T} 22$} & . & . & . & . & $\mathrm{T}$ & . & . & . & . & $5.0 \%$ \\
\hline & & \multicolumn{3}{|l|}{ * } & \multicolumn{3}{|c|}{ Leu } & \multicolumn{3}{|l|}{ * } & \\
\hline \multirow[t]{2}{*}{ RPMS1-C } & \multirow[t]{2}{*}{ T5 } & . & . & . & . & . & . & A & . & . & $50.0 \%$ \\
\hline & & \multicolumn{3}{|l|}{ * } & \multicolumn{3}{|l|}{ * } & \multicolumn{3}{|c|}{ Asn } & \\
\hline \multirow[t]{2}{*}{ RPMS1-C } & \multirow[t]{2}{*}{ T9 } & . & . & $\mathrm{C}$ & . & . & . & A & . & . & \\
\hline & & \multicolumn{3}{|l|}{+} & \multicolumn{3}{|l|}{ * } & \multicolumn{3}{|c|}{ Asn } & \\
\hline \multirow[t]{2}{*}{ Wt } & \multirow[t]{2}{*}{ T6 } & . & . & . & . & . & . & . & . & . & $45.0 \%$ \\
\hline & & \multicolumn{3}{|l|}{ * } & \multicolumn{3}{|l|}{$*$} & \multicolumn{3}{|l|}{$*$} & \\
\hline
\end{tabular}

Note: The top four rows were corresponding to the nucleotide, amino acid position, nucleotide and amino acid of B95-8 prototype sequence. In each row, the upper character denoted the nucleotide, which differed to the B95-8 prototype sequence. Conversely, the dot (.) denoted the same nucleotide compared to the referent sequence. The below characters indicated the amino acid written in three letter code that differed to the referent sequence. On the contrary, the " $*$ " character indicated the unchanged amino acid, and the "+" character indicated the silent amino acid changes. 
may exhibit stronger carcinogenesis potential leading to $\mathrm{NPC}^{16,20}$. In current study, among identified pattern of RPMS1, RPMS1-C/C*, counting for 50\%, was preferential in Vietnamese nasopharyngeal cancer. Therefore, it could be partly explained that the RPMS1-C/C* may contribute the high risk of NPC in Vietnamese population.

\section{Conclusion}

In summary, the significant association between the detection of RPSM1 gene and NPC incidence in Vietnamese NPC patients was determined. Of these, the frequency of RPSM1 gene was $66.67 \%$ in NPC clinical biopsy samples. Meanwhile, no positive case was detected in non-cancerous samples. Additionally, we successfully established the strategy to determine the RPSM1 gene variations in Vietnamese nasopharyngeal patients. Three RPMS1 gene variation patterns were identified in Vietnamese NPC patients. Among them, RPMS1-C was the preferred type in Vietnamese NPC patients. This approach may facilitate in identification of individuals who are at the high risk for NPC development, as well as further develop promising biomarker for prognosis, diagnosis and therapy for NPC based on the EBV gene variations.

\section{Acknowledgements}

We wish to express our thanks to the research project sponsored by Ho Chi Minh City Open University. We thank all the recruited participants in this work and Dr. Nguyen Trong Minh, Dr. Nguyen Huu Dung, and all the staff members of Otorhinolaryngology in Cho Ray hospital, Ho Chi Minh City, for collecting the samples used in these studies. We are thankful to the participants in our study and appreciated the contributions of the staffs from Molecular Biology Laboratory, Ho Chi Minh City, Open University, particularly, Nguyen Thanh Tung, Phan Dang Hoang Nam, Tran Hoang Bao Tran for their assistances.

\section{Ethics Approval and Consent to Participate}

All patients signed inform consent before entering into the study. No study drug or procedure was applied. This is an observational study.

\section{Conflict of Interest}

The authors declared that they have no competing interests.

\section{References}

1. Sham JS, Wei WI, Zong YS, Choy D, Guo YQ, Luo $\mathrm{Y}$, et al. Detection of subclinical nasopharyngeal carcinoma by fibreoptic endoscopy and multiple biopsy. Lancet. 1990; 335(8686):371-4. https:// doi.org/10.1016/0140-6736(90)90206-K.

2. Chang ET, Adami HO. The enigmatic epidemiology of nasopharyngeal carcinoma. Cancer Epidemiol Biomarkers Prev. 2006; 15(10):1765-77. https://doi.org/10.1158/10559965.EPI-06-0353. PMid:17035381.

3. GLOBOCAN. Estimated cancer incidence, mortality and prevalence worldwide in 2012. Available from: http://globocan.iarc.fr/Pages/fact_sheets_population.aspx.

4. Tsao SW, Yip YL, Tsang CM, Pang PS, Lau VM, Zhang $\mathrm{G}$, et al. Etiological factors of nasopharyngeal carcinoma. Oral Oncol. 2014; 50(5):330-38. https://doi.org/10.1016/j. oraloncology.2014.02.006. PMid: 24630258.

5. Lao TD, Truong PK, Le THA. miRNA-141 as the Biomarker for Human Cancers. AJPRHC. 2018; 10(2):42-49. https:// doi.org/10.18311/ajprhc/2018/21486.

6. Lao TD, Nguyen DH, Le THA. Study of mir-141 and its Potential Targeted mRNA PTEN Expression in Nasopharyngeal Carcinoma: From in Silico to Initial Experiment Analysis. AJPRHC. 2018; 10(3):66-74. https:// doi.org/10.18311/ajprhc/2018/22341.

7. Lao TD, Nguyen TV, Nguyen DH, Nguyen MT, Nguyen $\mathrm{CH}$, Le THA. miR-141 is up-regulated in biopsies from Vietnamese patients with nasopharyngeal carcinoma. Braz Oral Res. 2018; 32:e126. https://doi.org/10.1590/18073107bor-2018.vol32.0126.

8. Hildesheim A, Levine PH. Etiology of nasopharyngeal carcinoma: a review. Epidemiol Rev. 1993; 15(2):466-85. https://doi.org/10.1093/oxfordjournals.epirev.a036130. PMid: 8174667.

9. Wu S, Liu W, Li H, Zhao Z, Yang Y, Xiao H, et al. Conservation and polymorphism of EBV RPMS1 gene in EBV-associated tumors and healthy individuals from endemic and non-endemic nasopharyngeal carcinoma areas in China. Virus Res. 2018; 250:75-80. https://doi. org/10.1016/j.virusres.2018.04.009. PMid: 29665370.

10. Young LS, Dawson CW, Eliopoulos AG. The expression and function of Epstein-Barr virus encoded latent genes. Molecular Pathology. 2000; 53(5):238-47. https:// doi.org/10.1136/mp.53.5.238. PMid: 11091847, PMCid: PMC1186976. 
11. Marquitz AR, Raab-Traub N. The role of miRNAs and EBV BARTs in NPC. Semin Cancer Biol. 2012; 22(2):166-72. https://doi.org/10.1016/j.semcancer.2011.12.001. PMid: 22178394, PMCid: PMC3340885.

12. Gilligan KJ, Rajadurai P, Lin JC, Busson P, Abdel-Hamid M, Prasad U, et al. Expression of the Epstein-Barr virus BamHI A fragment in nasopharyngeal carcinoma: evidence for a viral protein expressed in vivo. J Virol. 1991; 65(11):6252-59.

13. Smith PR, de Jesus O, Turner D, Hollyoake M, Karstegl CE, Griffin BE, Karran L, Wang Y, Hayward SD, Farrell PJ. Structure and coding content of CST (BART) family RNAs of Epstein-Barr virus. J. Virol. 2000; 74(7):3082-92. https://doi.org/10.1128/JVI.74.7.3082-3092.2000. PMid: 10708423, PMCid: PMC111807.

14. Hui KF, Chan TF, Yang W, Shen JJ, Lam KP, Kwok H, Sham PC, Tsao SW, Kwong DL, Lung ML, Chiang AKS. High risk Epstein-Barr virus variants characterized by distinct polymorphisms in the EBER locus are strongly associated with nasopharyngeal carcinoma. Int. J. Cancer. 2018; [Epub ahead of print]. https://doi.org/10.1002/ijc.32049.

15. Chao M, Wang HN, Lu YJ, Chang YS, Yu JS. The V-val subtype Epstein-Barr virus nuclear antigen 1 promotes cell survival after serum withdrawal. Oncol Rep. 2015; 33(2):958-66. https://doi.org/10.3892/or.2014.3625. PMid: 25434292.

16. Feng FT, Cui Q, Liu WS, Guo YM, Feng QS, Chen LZ, Xu M, Luo B, Li DJ, Hu LF, Middeldorp JM, Ramayanti O, Tao
Q, Cao SM, Jia WH, Bei JX, Zeng YX. A single nucleotide polymorphism in the Epstein-Barr virus genome is strongly associated with a high risk of nasopharyngeal carcinoma. Chin. J. Cancer. 2015; 34(12):563-72. https://doi. org/10.1186/s40880-015-0073-z.

17. Lao TD, Nguyen DH, Nguyen TM, Le TAH. Molecular Screening for Epstein-Barr virus (EBV): Detection of Genomic EBNA-1, EBNA-2, LMP-1, LMP-2 Among Vietnamese Patients with Nasopharyngeal Brush Samples. Asian Pac. J. Cancer Prev. 2017; 18(6):1675-1679.

18. Cui Q, Feng FT, Xu M, Liu WS, Yao YY, Xie SH, Li XZ, Ye ZL, Feng QS, Chen LZ, Bei JX, Feng L, Huang QH, Jia WH, Cao SM, Chang ET, Ye W, Adami HO, Zeng YX. Nasopharyngeal carcinoma risk prediction via salivary detection of host and Epstein-Barr virus genetic variants. Oncotarget. 2016; 8(56):95066-74. https://doi. org/10.18632/oncotarget.11144.

19. Yap YY, Hassan S, Chan M, Choo PK, Ravichandran M. Epstein-Barr virus DNA detection in the diagnosis of nasopharyngeal carcinoma. Otolaryngol Head Neck Surg. 2007; 136(6):986-91. https://doi.org/10.1016/j. otohns.2006.11.027. PMid: 17547993.

20. Zhang J, Chen H, Weinmaster G, Hayward SD. EpsteinBarr virus BamHi-a rightward transcript-encoded RPMS protein interacts with the CBF1-associated corepressor CIR to negatively regulate the activity of EBNA2 and NotchIC. J. Virol. 2001; 75(6):2946-56. https://doi. org/10.1128/JVI.75.6.2946-2956.2001. PMid: 11222720, PMCid: PMC115921. 